rated margin, was seen a continuous and complete chain of small vesicles, filled with a thin, transparent fluid. The lymphatic vessels on that side of the face appeared extensively involved in the inflammation. The swelling had extended upward, entirely clos. ing the left eye, and cmbracing the parotidean and submaxillary regions. The tongue was heavily coated, the pulse more than 100 in the minute, and not strong.

We were unanimous in pronouncing it a malignant pustule.

The treatment which was at once instituted, consisted in making a crucial incision through the indurated and central portion, and thoroughly canterizing it with an iron heated to a white heat. The side of the face was corered with a blister, followed by an emollient poultice. A purge of calomel with bi-carbonate of soda was given. The next day, the patient was put upon the sulphate of quinine, one grain every three hours, and beef-tea occasionally. This treatment was continued. On the fourth or fifth day the patient was considered convalescent, and the visits were discon. tinued.

It may be well to mention that the family of the patient had a cow affected with some filthy and wasting disease, running at the nose, and abscesses about the neck and throat. They were obliged to kill her in the early part of September.

Waterville, Me., Nov. 1, 1859.

J. F. Noyes.

\title{
TWO CASES OF UNUSUAI DISCHARGE OF CARBONACEOUS MATTER FROM THE NARES AND INTESTINES.
}

BY M. BROKE GALLWEY, ESQ., ROYAL ARTILLERY.

The profession is indebted to Dr. Druitt for an able and very practical paper, introduced to its notice in a contemporary journal, on a Morbid Condition of the Nasal Passages; which, while it is a source of great uneasiness, on moral grounds, to the patient, is not unfrequently the occasion of much embarrassment to the physician. There are but few practitioners of any experience who have not been consulted on such cases; and, in the higher walks of life, a young aspirant for favor, consulted for the first time by a refined and fastidious patient, might make or mar his fortune, in proportion as he succeeded or failed in his recognition and management of such a case. The first time I encountered ozena myself was in the person of the butler of a capricious but sharp-witted old lady, to whom her farorite domestic had become a personal inconvenience from the ailment in question, and who pressed mo very hard for a categorical explanation of the fons et origo mali in this case. Having but rery latcly escaped from the schools, and being but an indifferent match, as a tactitian, for my subtle inquisitor, I unluckily winced, if, indeed, I did not ingenuously ad. mit my ignorance of the cașe, and fell in consequence fifty per Vox. LXI.-No. 18** 
cent. in the eyes of my tormentor. I say, then, that Dr. Druitt has done good service to medicine and to his junior brethren by his seasouable exposition of a tiresome and embarrassing complaint. I avail myself of the occasion to put on record, very briefly, the details, not of a case in point, but of a remarkable discharge from the nostrils, which lately fell under my notice, and which to myself is as unique as it is anomalous in its nature.

A married lady, having occasion suddenly to use her pockethandkerchief, discovered the latter to have become the recipient, from both nostrils, of a quantity of dry and intensely black powder, as exactly resembling soot (the term she applicd to it herself), or finely levigated charcoal, as any two distinct substances could well resemble each other. This discharge was unpreceded and unattended by coughing, pain, uneasiness, or by any other physical indication of the presence of forcign matter in the nose or throat. De plus, it appeared to come from the part, and not from a distance ; certainly not from the lungs or bronchial glands, being unpreceded by cough. Moreover, it was not only not suspended in the nasal secretion, but, on the contrary, was deposited on the handkerchief as a dry carbonaceous powder. This curious state of things had presented itself on five several occasions in the course of nine months, and at different periods of the day and night. The subject of it had not been using charcoal as a dentifrice, nor exposed to the fumes of that substance in any way; indeed, on each occasion it occurred in the summer months, and when removed from the influence of fires of every kind. Wili Dr. Druitt, or any other physiologist, enlighten us with the rationale of this occurrence? My patient has, from time to time, been much troubled with acne punctata on the external nares, as well as on the back and shoulders. Her temperament is one in which nerve preponderates largely over blood; her agc, between thirty-fire and forty. Is it possible for the system to disembarrass itself of carbon in excess in a solid form, and by such anomalous outlets as the nose; the mucous membrane, in this direction, becoming vicarious to the ordinary channels that discharge this element from the body?

Although not falling legitimately within the same category of morbid changes, I shall avail myself of the opportunity also to record a case of deposit of a sooty discharge from the vessels of another mucous membrane, at a considerable distance from the foregoing. I had administered but a single three-grain dose of the ammoniated citrate of iron to a married lady, aged about forty-five, when I was summoned, the morning after, in great alarm, to account for a sudden and enormous discharge from the bowels of what she described to me as soot, and which she had preserved for my inspection. On examining the vessel into which it had been passed, I was not a little surprised to find its interior beameared throughout with what exactly resembled soot to the eye, 
a quantity of the same being suspended in a watery alvine evacuation with which it had come away; the patient having been for some time under my hands for diarrhœe, connected with an atonic state of the chylopoietic functions, and, I may say, of the general system at large. The influence of iron in blackening the stools being so very different, in general, from that excrcised in the present case, and operating only, in my own experience, after an interval of some days, I did not at first suspect this medicine of be. ing chargeable with the results before me-the less so, when I reflected upon the insignificance of the quantity my patient had taken (a single dose) -and accordingly desired her to persist in the use of the remedy; with the result, however, of augmented discharges of the same material. She then abandoned the medicine, and the sooty dejection began to disappear, although not un. til after an interval of two or three days subsequent to its disuse. Has this singular effect of iron been witnessed before? and is it peculiar to the form in which I prescribed it? For twenty years I have prescribed the remedy pretty largely, but never with similar results before, or indeed with any other than a general blackening of the intestinal excreta. In the present case, the carbonaceous deposit diffused itself throughout the sides and bottom of the containing vessel, and was suspended on the surface of its contents, rather than internixed with the body of the latter.

Although selecting ozena as the text for my present paper, I shall venture very briefly to introduce another subject into it-not to trespass unnecessarily upon the crowded pages of The Lancet with a second contribution.

While penning the foregoing few observations, the discussion at the Medical Society of London upon some cases of sudden serere pain in the great toe, succeeded immediately afterwards by ecchymosis, more or less extensive, up the corresponding foot, has met my eye in the pages of the periodicals. I desire to add to the cases adduced on that occasion by different speakers, the following, which came under my notice:-

A married lady, of nervous temperament and feeble circulation, while sitting at dinner, on an intensely cold day, observed the back of one of her hands suddenly to becone discolored over an area of about three inches, the discoloration continuing to extend as she fixed her attention upon the part. Her hand had not sustained any violence, nor was there any departure whaterer from her customary state of health beyond the somewhat severe invasion of chilblains upon the feet. The back of her hand presented much the appearance of a severe bruise, save that the bluish-black appearance was not relieved by the usual variegated tinting of that condition. Neither pain nor tenderness preceded, accompanied, or followed it. In a fortnight it had disappeared.-Lon. Lancet. 